\title{
"Esta maravilha de cenário": as representações da cidade do Rio de Janeiro e seus habitantes na fotografia de moda
}

\author{
"Esta maravilha de cenário": \\ the representations of the city of Rio de Janeiro \\ and its inhabitants in fashion photography
}

\begin{abstract}
Virginia Todeschini Borges
Doutora em Artes Visuais pela Universidade Federal do Rio de Janeiro (2008), mestrado em Comunicação pela Universidade Federal do Rio de Janeiro (2003) e graduação em Comunicação Social, habilitação em Jornalismo, pela Universidade Federal do Rio de Janeiro (1999). Tem experiência como professora nas disciplinas Teorias da Comunicação, Novas Mídias, Metodologia de Pesquisa, Trabalho de Conclusão de Curso; e também como pesquisadora nas áreas de Comunicação e Cultura e Artes Visuais, com ênfase nos seguintes temas: Jornalismo de moda, Moda e Comunicação, Moda e imaginário urbano no Rio de Janeiro.
\end{abstract}

\section{RESUMO}

A cidade do Rio de Janeiro é considerada um centro difusor de moda, inovações, modismos, cultura. Até mesmo quem nunca colocou os pés na cidade tem um julgamento a respeito dos estilos de vida locais e de seus habitantes. Sede de um dos principais eventos do calendário brasileiro de lançamentos, o Fashion Rio, é do Rio que saem as maiores tendências da temporada primaveraverão. O objetivo deste artigo é analisar as representações da cidade, dos seus habitantes e dos estilos de vidas locais por meio das fotografias que circulam nas principais publicações de moda; imagens essas que repercutem no imaginário visual brasileiro, através das mediações exercidas pelos meios de comunicação.

Palavras-chave: corpo; moda; fotografia; Rio de Janeiro.

\section{ABSTRACT}

Rio de Janeiro is considered a diffusion center of fashion innovations, fads, culture. Even those who have never been in the city has a judgment about the local lifestyle and its inhabitants. The city hosts one of the main events of the Brazilian fashion calendar, Fashion Rio, Rio is a trendsetting in the springsummer season. The purpose of this article is to analyze the representations of the city, its people and lifestyles through photographs circulating in major fashion publications; imagens that reflect the brazilian visual imagery, through the mediation exercised by the media.

Keywords: body; fashion; photograph; Rio de Janeiro. 


\section{Introdução}

Especialmente no verão, as revistas femininas e as especializadas em moda têm como pauta a moda carioca. Grande parte dessas imagens apresentam pontos em comum - clima tropical, cenário de cartão-postal, roupas vaporosas, que revelam os corpos - ingredientes de uma receita que reproduz um ideal estético constantemente atribuído ao carioca.

Os corpos expostos são, sobretudo, os femininos (mesmo porque a maior parte das publicações de moda tem como público-alvo as mulheres). Nos editoriais de moda que elegem a cidade do Rio de Janeiro como cenário predomina a mulher pouco vestida, bronzeada, em poses sensuais, a eterna Garota de Ipanema. E a moda carioca é considerada pelos especialistas e pelos consumidores como sensual e mesmo despojada - roupas que vão da praia ao shopping, ao teatro, ao cinema, ao barzinho, ao restaurante.

A cidade é quase sempre a eleita para apresentação da moda praia, da moda primavera-verão. Em outras épocas do ano, quando as páginas dos meios de comunicação impressos dão destaque ao vestuário invernal, raramente o Rio aparece como locação; pelo menos aquele Rio dos cartões portais.

Perguntamos: quais os aspectos do estilo carioca e da cidade são privilegiados numa produção de moda sobre o Rio de Janeiro? Para se vestir de forma sensual, expondo o corpo, é preciso ter o aval da cidade? Veste-se assim, mas não em todos os lugares. É preciso estar no Rio. Mas por que especialmente no Rio é assim?

Elegendo o Rio de Janeiro como palco privilegiado, nos debruçamos sobre o estudo das fotografias de moda feminina veiculadas em alguns dos principais periódicos de divulgação de moda, com o objetivo de analisar o papel destas representações do corpo e da moda na construção ou na reprodução de uma estética própria à cidade, que repercute no imaginário visual brasileiro, por meio das mediações exercidas pelos meios de comunicação de massa. 

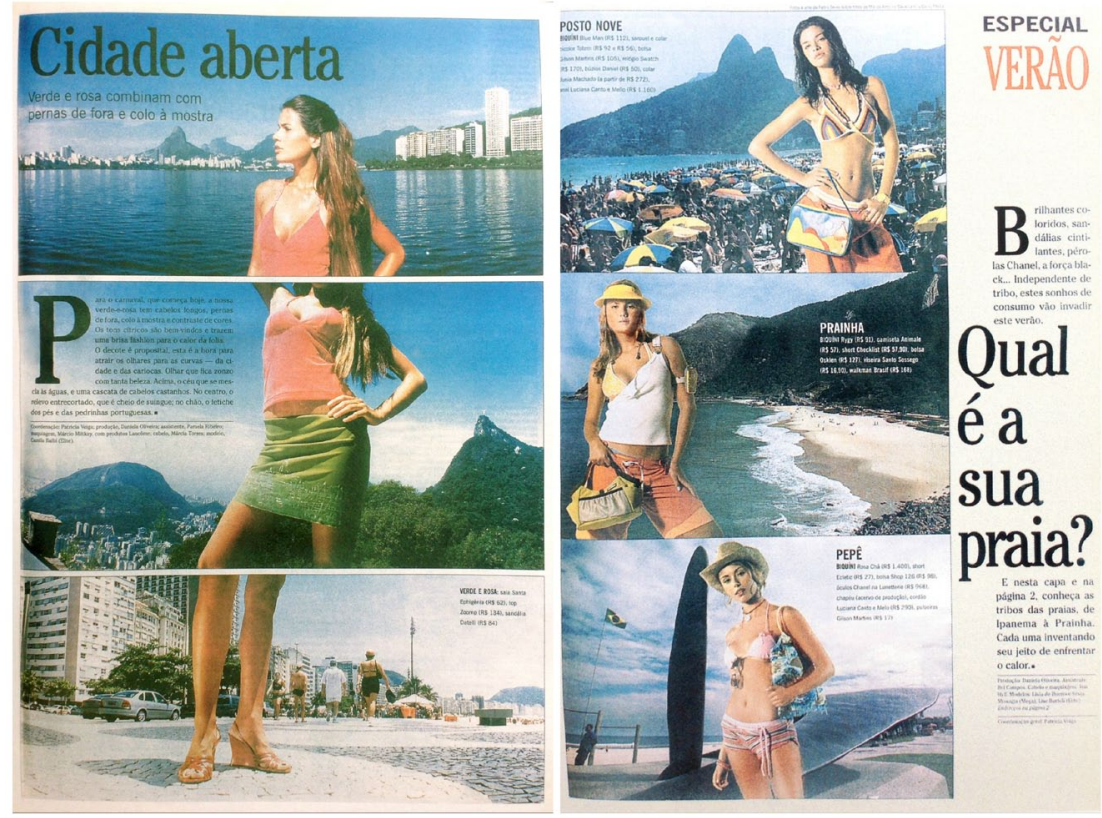

Figura 1 - Reproduções de primeiras páginas do caderno Ela.

Editoriais de moda e "Cidade aberta" (2000) e "Qual é a sua praia?” (2002).

O primeiro elemento observado nas fotografias é o cenário - a cidade do Rio de Janeiro. Especialmente no verão, os editoriais de moda de revistas femininas e jornais abandonam os estúdios e privilegiam cenários considerados mais próprios à estação — ao ar livre, com paisagens paradisíacas.

Barthes, no livro Sistema da moda (1979, p. 287), ressalta que a fotografia de moda é como um teatro. Sob um fundo ou uma cena, que é sempre temático, está uma mulher em ato. O décor aparece como um pretexto para a mulher que veste a roupa. Raramente encontra-se uma mulher vestida fora do contexto. Mesmo quando a modelo é fotografada em estúdio, sob fundo neutro, ela está atuando, como num teatro.

Assim, é a própria cidade do Rio que dá o aval de sensualidade e é pretexto para a exposição dos corpos. O palco é a praia, o calçadão, o parque, a presença do mar, as cenas que aludem ao verão, ao clima tropical. Há toda uma mise-en-scéne que permite, ou mais que isso, que sugere a composição de um vestuário despojado, sensual, revelador.

Os textos que acompanham as imagens dão ênfase às belezas e qualidades da cidade. Palavras não são poupadas quando se trata de elogiar a Cidade Maravilhosa. Nestes casos, o texto acrescenta significados segundos à fotografia. De acordo com Roland Barthes, no texto A mensagem fotográfica (1990, p. 311), o texto que acompanha a fotografia constitui uma mensagem destinada a conotar a imagem, ou seja, lhe imputar significados segundos. Não se trata de uma informação essencial à compreensão da imagem, 
como nas legendas jornalísticas. Assim, a palavra ajuda a ilustrar a imagem, enxerta-a de uma cultura, de uma moral, de uma imaginação, conferindo-lhe uma sorte de sensações.

Como exemplo, o texto que acompanha imagem do caderno Ela, unindo as formas dos corpos com as formas curvas da natureza (Figura 1):

Para o Carnaval, que começa hoje, a nossa verde-e-rosa tem cabelos longos, pernas de fora, colo à mostra e contraste de cores. Os tons cítricos são bem-vindos e trazem uma brisa fashion para o calor da folia. O decote é proposital, esta é a hora para atrair os olhares para as curvas - da cidade e das cariocas. Olhar que fica zonzo com tanta beleza. Acima, o céu que se mescia às águas, e uma cascata de cabelos castanhos. No centro, o relevo entrecortado, que é cheio de suingue; no chão, o fetiche dos pés e das pedrinhas portuguesas. (CIDADE, 2000, p. 1)

Os textos das legendas dão vida às imagens. Inúmeros são os adjetivos empregados para se pôr em evidências as belezas da cidade do Rio de Janeiro, atribuindo-lhe qualidades, adjetivos, de características humanas, ou apenas descrevendo, como poetas, aquilo que agrada ao olhar. Suas montanhas são comparadas às curvas femininas. A maresia cheira a doce. Tudo parece transpirar sensualidade.As palavras despertam os sentidos e as imagens ganham cheiros, sons, gostos, texturas. De cenário, a cidade passa a personagem; algumas vezes, protagonista.

A edição brasileira da Vogue dedica, anualmente, uma edição ao Rio, à ocasião do verão. Nas palavras do jornalista Ignácio de Loyola Brandão, à época diretor de redação, "esta é uma revista que tem jeito carioca em sua espinha dorsal”. Em editorial, ele escreve:

Esse Rio que continua uma cidade provocante, cheia de adrenalina, que mexe com o erotismo e tem um jeito maroto. Cidade que amamos pelo calor, pelo frescor, pela beira-mar, pelo cheiro doce e grudento das noites de maresia, pelo calçadão, pelo jeito de falar, pelo relaxamento, pelo mar, pela bermuda e chinelinho. Enfim, amamos o Rio, que Vogue traz na sua edição anual dedicada à cidade. (BRANDÃO, 2001, p. 165)

O clima de festa e carnaval também é constantemente empregado neste tipo de editorial de moda. Lança-se mão de penas, plumas, paetês. As produções viram verdadeiras alegorias que dificilmente fariam parte do guarda-roupa das leitoras destes tipos de publicação.

E como no Rio tudo tem a capacidade de virar moda, de bolsas falsificadas às calças de dançarinas de funk, o glamour da Zona Sul é, por vezes, substituído pelo cenário da favela. $O$ trânsito das tendências não respeita mais à clássica pirâmide de difusão de modas tão empregada nas antigas análises sobre o fenômeno da moda, onde as classes superiores, no topo da pirâmide, se distinguem das classes inferiores, abandonando os 
modelos já difundidos em direção à base da pirâmide por modelos novos. Hoje, o movimento também é ascendente.
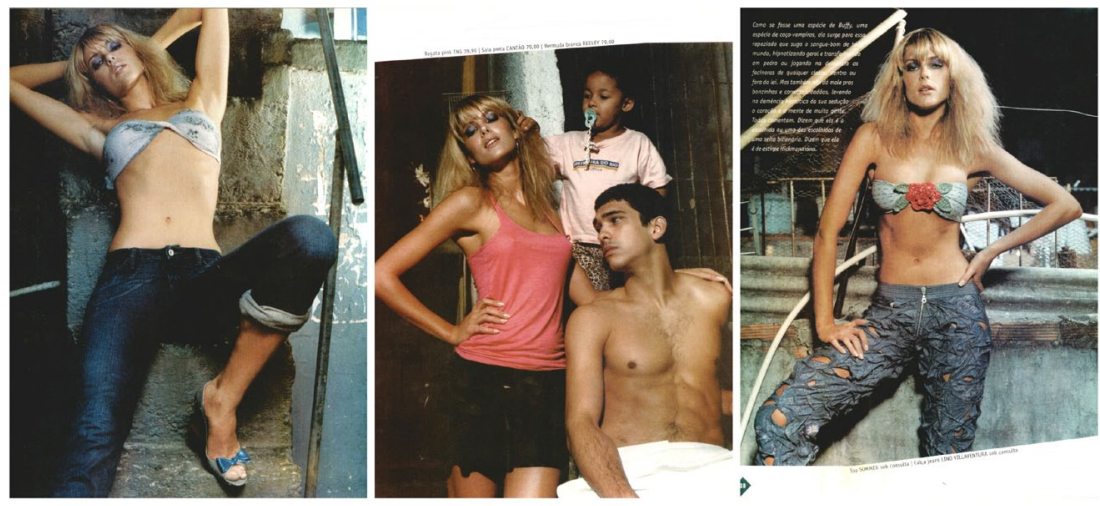

Figura 2 - Reproduções do editorial de moda da revista Glam Rio, intitulado

"A Faveloura Hickmanniana" (2003).

No editorial da revista Glam Rio intitulado "A Faveloura

Hickmanniana", as ruelas e os becos das favelas, a decoração do interior dos barracos, as paredes sem revestimento, construções abandonadas também servem de cenário para ambientar roupas tropicais, vaporosas, inspiradas no look das meninas pobres. (Figura 2) A estética da pobreza, da favela, também vem acompanhada do clima de sensualidade, mas sem jamais perder o luxo que caracteriza as fotografias de moda.

As imagens mostram como a roupa e a exibição dos corpos apresentam-se sob o aval de um décor específico. No caso, é a cidade do Rio, que, devido as suas próprias características culturais, permite o uso determinada forma de trajar e de se exibir aos demais.

\section{A sensualidade na cultura local}

$\mathrm{Na}$ cidade, o corpo, vestido ou desvestido, está sempre presente nas mais diversas situações urbanas: na praia, na calçada, nos shoppings, no trânsito, no trabalho. O corpo é a base onde o carioca constrói e exibe o que considera particularmente ideal, assumindo-o como instrumento principal de expressão, compondo uma estética própria. Isso se reflete na moda.

Toda essa "encenação" de conotação sexual possui um respaldo sociocultural. A sensualidade, a sedução pelas formas e pelos movimentos são características constantemente atribuídas ao brasileiro. Tomando de empréstimos as palavras de Jean Duvignaud (1998, p. 1), esta "superabundância afetiva, sensual" desafia seguidamente as estatísticas ou as classificações. O Brasil é mesmo o país dos paradoxos, da diversidade, da multiplicidade de grupos e etnias — uma sociedade pluralista, onde a sensualidade faz parte das relações sociais e do imaginário da população, refletindo-se nas imagens e na literatura sobre os Brasis que compõem o Brasil. 
Segundo Gilberto Freyre (2002, p. 19-20), em Modos de homem \& modas de mulher, "uma das características das modas de mulher é representarem feminilidade", como graça, delicadeza, atração sexual. O autor acredita que as modas brasileiras tendem a ser ecológicas - de acordo com o clima brasileiro: um clima tropical e, no Rio de Janeiro, oceânico —, femininas e adaptadas ao tipo antropológico — a morenidade e o bronzeamento. (FREYRE, 2002, p. 35)

No caso específico do Rio, o expoente da criação de moda local é a moda praia. Os biquínis cariocas são referência no mundo inteiro. Da mesma forma, as roupas tendem a ser mais leves, mais curtas, uma moda de balneário. Nas palavras do antropólogo francês Stéphane Malysse, (2002, p. 82) "o clima tropical favorece uma liberação do peso das roupas e uma tomada de consciência visual do corpo ao mesmo tempo mais direta e mais intensa".

E assim como há modas de roupas, há também modas de beleza. A brasileira é considerada uma das mais belas do planeta - graças, em grande parte, ao sucesso das modelos brasileiras no exterior —, embora seja vista de maneira muito estereotipada. O filósofo francês Gilles Lipovetsky (2004), em entrevista concedida ao Jornal do Brasil, acredita que as modelos brasileiras têm espaço no mercado de moda global por serem sensuais, terem cor, beleza e ritmo. $\mathrm{Na}$ opinião dele, essa imagem do sol é muito importante para o Brasil.

A este respeito, a estilista de moda praia Lenny Niemeyer declarou ao jornal $O$ Globo que "as americanas querem ser brasileiras, estiradas na praia, com um biquíni tropical. (CEZIMBRA, 2003) Só serve se for biquíni brasileiro, pequeno e cavado. Elas querem ser aquela brasileira linda, deitada na areia de Ipanema".

A cidade dá o aval de sensualidade e é pretexto para a exposição dos corpos. O palco é a praia, o calçadão, o parque, as cenas que aludem ao verão e ao clima tropical. Há toda uma mise-en-scéne que sugere a composição de um vestuário despojado, sensual, revelador. Ou seja, a cidade, devido as suas próprias características culturais, ecológicas e geográficas — oceânica e tropical —, permite o uso de determinada forma de trajar e de se exibir aos demais.

\section{Corpos em cena no Rio de Janeiro}

A revista Vogue Brasil tradicionalmente dedica a edição de novembro à cidade, consagrando-a como do a capital do verão:

O Rio de Janeiro nos lembra as vamps hollywoodianas que eram sensuais, acenavam com perigos, porém, sendo fascinantes, todos se entregavam a elas, mergulhando em grandes paixões. Não há como não se render a essa cidade 
que conserva seu brilho, se savoir-vivre, seu ar blasé e o humor irretocável. Uma vez conquistada, a pessoa se torna cativa. (...) A Vogue dedicada ao Rio é uma tradição, em novembro. (BRANDÃO, 2004)

Cada vez mais lindo, o Rio é o cenário para a edição de um verão radicalmente tropical. Tem funkeira fashion, tem o universo de Debret, tem mulheres rendeiras, tem até um certo esnobismo que, claro, Vogue transforma em experiência legal. (CARTA, 2004)

Dentro deste cenário, que retrata, em geral, as belezas naturais do Rio de Janeiro, identifica-se a presença de uma carioca sensual e de uma moda leve, despojada, própria para ser usada nos momentos de lazer, à beira da praia ou da piscina, em passeios pelos pontos turísticos. É um look que também se estende à vida urbana.

Qual o enfoque normalmente dado às produções de moda que destacam o Rio de Janeiro? Que aspectos da cidade e de seus habitantes são privilegiados quando a imprensa de moda se refere à moda carioca, a um estilo carioca, sobretudo em relação à representação da mulher carioca?
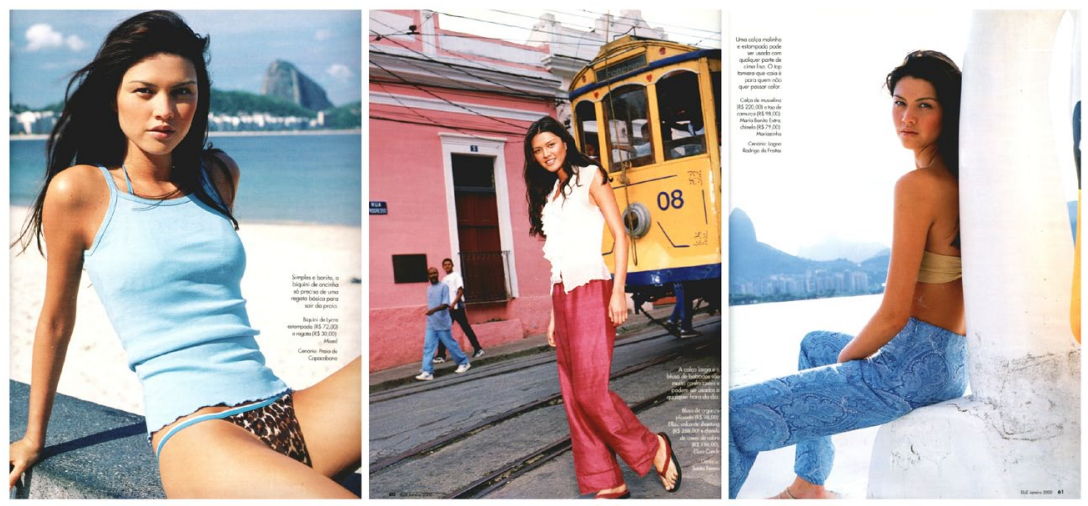

Figura 3 - Reproduções de editorial de moda da revista Elle intitulado

“O melhor do verão" (2000).

Como em editorial da revista Elle intitulado O melhor do verão: "As roupas que você vê aqui são tão indispensáveis quanto o protetor solar. Há peças para todas as ocasiões, da praia à noite. Em comum, a leveza e a sensualidade típicas da estação - e perfeitas para um passeio no Rio de Janeiro". (O MELHOR, 2000) As imagens sugerem um clima de férias, de passeio, de lazer, com a mulher aproveitando o sol e os dias quentes de verão.

Um aspecto fortemente explorado nessas produções de moda é a exposição dos corpos, o jeito carioca de se vestir com poucas roupas, peças leves e justas. Os textos que acompanham as fotografias apresentam os seguintes ingredientes: corpo, sol, mar, praia, Rio, verão. Como: “Com banca de garota de Ipanema, a moça desfila o melhor de verão em cores e estampas iluminadas pelo Rio". (Figura 4) Ou ainda: "Corpo, sol, sal elevam 
a temperatura das areias cariocas". (Figura 6)

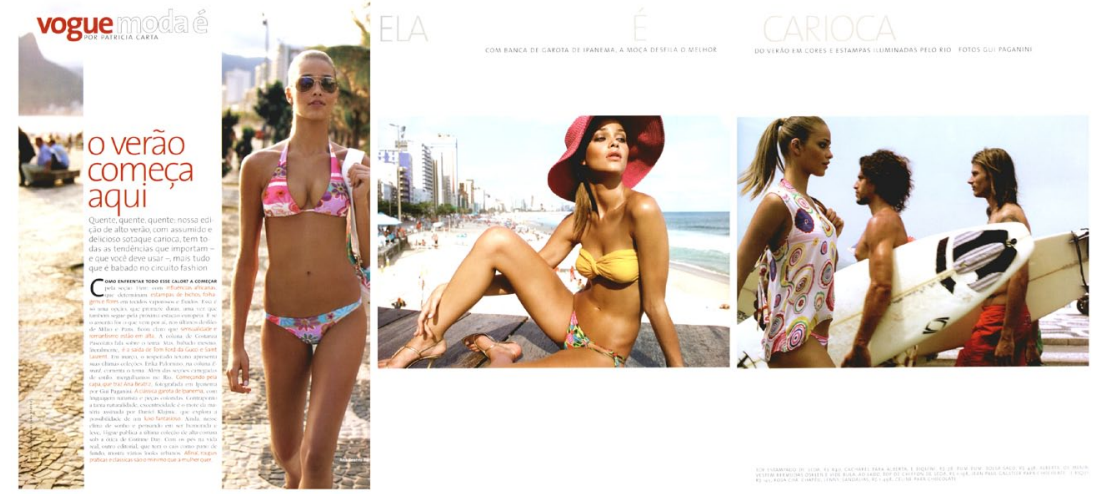

Figura 4 - Reproduções do editorial de moda "Ela é carioca" (2003), da revista Vogue Brasil.

Em editorial da Vogue Brasil, Ignácio de Loyola Brandão acrescenta os corpos ao cenário da cidade: "Assim, a moda verão aqui surge impregnada fortemente pela sensualidade exacerbada de corpos ardentes, ao mesmo tempo que cores suaves flutuam em velhos casarões”. (BRANDÃO, 2001)

Qual é o perfil da mulher carioca que emerge das páginas dos editoriais? Em geral, é uma mulher magra, em forma, sensual, jovial (mesmo porque as modelos são sempre jovens e magras), alegre.

No editorial, "RIO, le grand", publicado na Vogue America, o fotógrafo Mario Testino retrata um tipo de mulher jovem, saudável, alegre, descompromissada e sensual. (Figura 5) É um clichê que está muito arraigado na imagem do Rio. Essas imagens que traduzem o estilo de vida da Zona Sul da cidade e o clima de alegria e sensualidade que também são características de seus trabalhos.
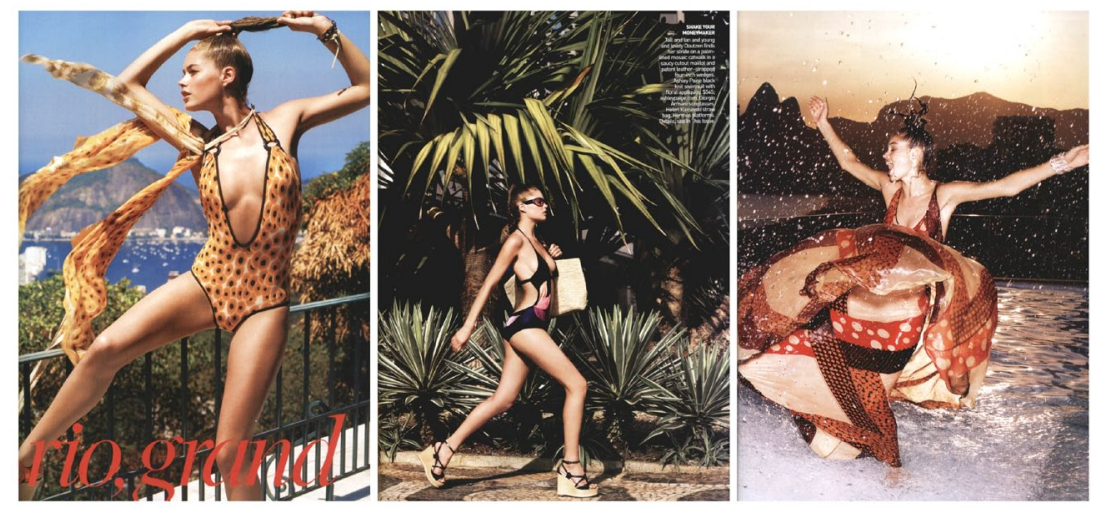

Figura 5 - Reproduções do editorial de moda "Rio, le grand" (2007), da revista Vogue America. 
Nas fotografias ambientadas no Rio de Janeiro, a modelo encarna uma mulher em poses sensuais e pouco vestida. É uma profusão de pernas, barrigas, colos à mostra. No imaginário brasileiro as mulheres cariocas se vestem sensualmente em praticamente qualquer ocasião, até mesmo para fazer compras nas feiras livres

Vale destacar a presença masculina nestas fotografias. Os homens são, quase sempre, malhados e posam, quase sempre, com o dorso à mostra. Mas eles são um mero complemento estilístico, apenas coadjuvantes, observando a bela mulher que passa ou como acompanhante nas cenas mais sensuais, como no editorial “A Faveloura Hickmannian” (Figura 2).

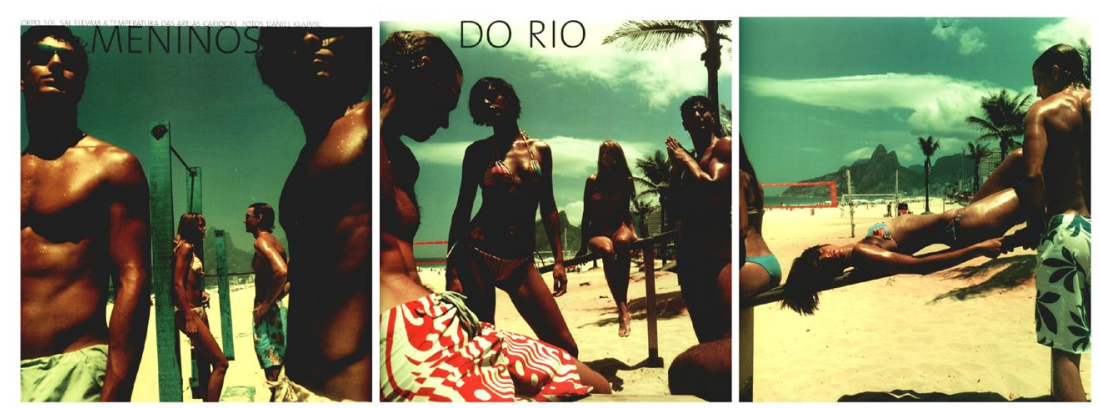

Figura 6 - Reproduções do editorial de moda "Meninos do Rio" (2001), da revista Vogue Brasil.

Em "Meninos do Rio", na Vogue Brasil, os modelos se assemelham a bonecos ou manequins de vitrine, simulando atividades físicas na praia. (Figura 6) As fotografias aqui são mais estáticas, não há a sugestão de movimento dos outros editorias. $\mathrm{O}$ uso de filtros deixa a atmosfera irreal, assim como os modelos. É um reino de fantasia.

Trata-se de um preito à malhação e ao culto à boa forma física. A praia de Ipanema é o local ideal para malhar, paquerar, tomar sol, mergulhar, ver e ser visto, tudo ao mesmo tempo. O palco e os seus personagens são montados tal como a vida parece ser conduzida na nossa cidade, ajudando a vender esta imagem paradisíaca do Rio. Mas os corpos reais são substituídos por corpos ideais. A cena é "higienizada": não há crianças, idosos, gordos, vendedores ambulantes, turistas, apenas jovens cuja forma física é invejada e almejada pela nossa sociedade. Uma simples caminhada "ao vivo" no calçadão revela que a vida real não é exatamente assim.

Toda esta encenação se dá com base em alguns estereótipos: a moça do baile funk, a garota de Ipanema ou as passistas e destaques de carnaval são algumas das personagens cariocas mais referenciadas. A mídia utiliza largamente o clichê, o lugar-comum, com a finalidade de assegurar uma fácil compreensão das imagens. Segundo o sociólogo Irving Goffman (1977), 
no artigo La ritualisation de la féminité, a respeito da fotografia publicitária na perpetuação do comportamento ligado aos gêneros, a tarefa do publicitário é promover o produto em um cenário encantador. O elemento encantador é assegurado pela presença de uma mulher bela, elegante, jovem, seja o produto uma vassoura, um inseticida ou um cartão de crédito. A mulher parece transferir suas qualidades ao objeto. A imprensa de moda não faz diferente. São imagens facilmente reconhecidas em qualquer lugar: a executiva, a mãe de família, a mulher fatal, a adolescente, a romântica.

Comumente ligados a ideias de comportamento, atitude, estilo de vida, este material prolifera um ideal de corpo. Todos os modelos seguem o padrão de beleza atual: magros ou levemente malhados, sem exceção. Em muitas das fotografias as modelos portam roupas curtas, justas, decotadas, ou roupas de praia. O tom da pele é levemente bronzeado. O clima é de despojamento e sensualidade, bem tropical. A fórmula é quase sempre a mesma: Riotcorpo+calor=sensualidade.

No editorial "Ela é carioca" (Figura 4), as fotos sugerem o movimento. A modelo parece desfilar ao som da música: "É ela, menina, que vem e que passa. Num doce balanço, a caminho do mar". A sensualidade aqui pede um balançado, como na canção de Tom e Vinicius. A indumentária de banho, com o acréscimo de algumas peças, vira roupa se passeio.

Por vezes, a (pouca) roupa não condiz com a ocasião, aparece descontextualizada, num cenário que não lhe é próprio, como, por exemplo, em fotografias onde a modelo veste maiôs num local pouco provável para um banho de sol, de mar ou de piscina, como numa feira livre.

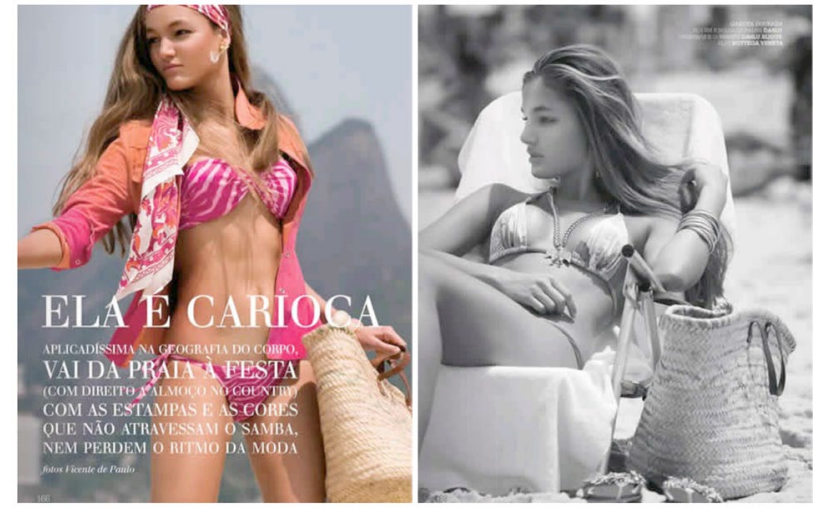

Figura 7 - Reproduções do editorial de moda "Ela é carioca" (2007), da Revista Daslu.

O que se encontra comumente nos produtos da mídia é a reprodução de estereótipos, de clichês. Os corpos precisam ser belos, esguios, devem transpirar sensualidade e dar a impressão de que são bem 
sucedidos, tanto econômico quanto sexualmente. Não é o reflexo da realidade de quem consome estes produtos, mas é baseado num ideal de beleza aceito e valorizado pela sociedade. Meninas e mulheres, cada vez mais, submetem-se a regimes e dietas alimentares para se adequar aos padrões estéticos difundidos pela mídia.

Para Mirian Goldenberg (2001), o corpo se tornou "o mais belo objeto de consumo". A publicidade, por exemplo, que antes exaltava as qualidades de determinado produto, hoje em dia serve, principalmente, para produzir o consumo como estilo de vida. E acabou dando origem a um produto próprio: o consumidor, eternamente insatisfeito com a sua aparência.

Ou seja, a mídia propaga determinado padrão estético, mas isso não deixa de ser um reflexo dos desejos da própria sociedade. Ela difunde determinados valores desde que se tenha público para isso. Todas querem se parecer com a garota da capa.

Segundo Roland Barthes, em Sistema da moda (1979, p. 245), a moda tem, a cada ano, a tarefa de decretar que certos corpos (e não outros) estão na moda. Ela igualmente tende a ajeitar o vestuário, de modo que ele transforme o corpo real no corpo ideal da moda: alongando, diminuindo, afinando, aumentando.

O acessório mais significante para a roupa é um corpo voluptuoso, um corpo idealizado que está a serviço da moda. Pensando nisso, os estilistas fazem roupas transparentes, com decotes e fendas pensando num determinado padrão estético. Segundo Jean Baudrillard (1996, p. 151), em $A$ troca simbólica e a morte, "agora é o próprio corpo, na sua identidade, no seu sexo, no seu estatuto, que se tornou material da moda — o vestuário não passa de um caso particular".

Portanto, falar em moda não é falar apenas da roupa propriamente dita. Ela se refere à aparência de uma forma geral - ao vestuário, a todo e qualquer tipo de ornamentação e estratégias corporais, como a exigência de se manter em forma, as marcações e perfurações corpóreas.

A moda não quer mais vestir o corpo, ela cria um corpo que lhe sirva de complemento. A pergunta que fica é: qual corpo é o mais adequado para a moda?

O retratado nos editorias é de modelos altas e magras. As manequins parecem verdadeiros cabides a serviço dos estilistas. A maquiagem e outros recursos empregados na fotografia - como a fotogenia, pose, iluminação são capazes de corrigir qualquer imperfeição. A modelo da foto é um ideal que jamais será atingido pelas leitoras, nem pela própria modelo, quando fora do contexto da fotografia.

O acessório mais significante para a roupa é um corpo voluptuoso, 
um corpo idealizado que está a serviço da moda. Tanto que os estilistas fazem roupas transparentes, com decotes e fendas pensando num determinado padrão estético.

Observa-se uma hipervalorização do corpo na cultura carioca, que não é uma característica exclusiva desta cidade, mas da contemporaneidade. Só que no Rio de Janeiro este corpo está em cena para ser mostrado, por meio de um vestuário tropicalmente leve e sedutor.

A exposição dos corpos é ponto elementar no cotidiano do carioca - na praia, nas áreas de lazer ao ar livre, nas academias, nas ruas, sobretudo no verão, que parece se prolongar ao longo do ano. A cultura corporal carioca é avessa à gordura e à velhice, exalta a boa forma física e a juventude. A temperatura elevada durante quase todo o ano favorece o desnudamento do corpo e, conseqüentemente a exigência de se manter em forma.

Na opinião de Mirian Goldenberg (2001), esta constante exposição dos corpos, não só na mídia como nas interações cotidianas, está associada à instauração de uma nova moralidade, de uma nova noção do que é decente e indecente, no que se refere ao vestuário. A utilização de uma indumentária que deixa à mostra determinadas partes do corpo, ou mesmo a exibição do corpo nu, não é considerada tão indecente quanto à exibição de um corpo 'fora de forma' ou o uso de roupas não condizentes com a forma física.

\section{Conclusão}

Apesar do caos urbano, da violência, de problemas de infra-estrutura, o Rio de Janeiro é mostrado pelas revista de moda como um local hospitaleiro, quente e sensual, semelhante ao discurso turístico, criando expectativas em relação ao que pode ser encontrado na cidade. Trata-se de uma abordagem atemporal, o Rio como cidade das férias de verão. Mudam-se as roupas - a moda transmite a ideia de atualidade - , mas a estrutura se mantém inalterada.

A moda circula sob o estágio da imagem. Este tipo de fotografia apresenta-se também como oportunidade de transmitir outras experiências, contar novas histórias e criar novas realidades, muitas vezes permeadas de sonhos e fantasias. Mais que um produto, a imagem é considerada uma experiência sensorial particular e única, como afirma Nelson Brissac Peixoto, no artigo As imagens e o outro (1990, p. 474): "cada imagem é uma referência num mapa que o explorador vai aos poucos traçando, um componente a mais no seu quadro imaginário".

Em linhas gerais, a moda da cidade que emerge das páginas das publicações de moda é baseada num clichê que envolve os seguintes elementos: praias, belas paisagens, corpos expostos, pessoas alegres, sensualidade, férias, lazer, festas, carnaval. Mas seria igualmente redutor afirmar que a moda apenas abusa dos estereótipos a respeito do carioca. Seria o mesmo que aceitar que toda a criação 
artística se baseia em ou dissemina estes mesmos estereótipos: como a canção Garota de Ipanema e inúmeras outras da música popular brasileira; as mulatas do caricaturista Lan e os acontecimentos quotidianos da cidade imortalizados pelos seus traços; as linhas sinuosas dos projetos de Oscar Niemeyer, de inspiração nas curvas femininas ou nos contornos da cidade. Todas as criações envolvem sentimentos, sensações, estados de espírito. Não podemos racionalizá-las, muito menos reduzi-las à mera reprodução de estereótipos.

Embora as representações acerca do Rio de Janeiro, seus habitantes e sua moda característica se revelem muitas vezes estereotipadas, tratam-se de idealizações de construções culturais que já estão dadas. Embora de conteúdo ficcional, essas imagens não rompem totalmente com a realidade, mantém sempre uma relação, por menor que seja, com o mundo real. As fotografias de moda analisadas ao longo desta pesquisa, utilizando as palavras de Goffman (1970, p. 49), não fazem mais que “convencionar as convenções", estilizar aquilo que já está dado.

São imagens que privilegiam a Zona Sul, a praia, os cenários de cartãopostal. Apresenta-se uma moda direcionada às camadas médias e altas da população. É preciso se ater ao fato de serem estas publicações direcionadas a um público-alvo que também é identificado, dentre outros fatores como gênero ou estilo de vida, pela renda - um leitor que consome e, mais precisamente, consome as marcas apresentadas nas revistas. As empresas sobrevivem com os anunciantes. A Zona Sul também é apontada no campo da moda como lançadora de tendências e modismos na cidade.

Estas imagens baseiam-se, como apontou Nízia Villaça (2008) no artigo Corpo à moda mídia na cidade do Rio de Janeiro, na cidade maravilhosa, no Rio de Janeiro paraíso tropical e no carioca enquanto habitante deste local aprazível; uma imagem construída no prestígio de outrora. Tudo isso faz parte da fantasia a respeito da cidade maravilhosa. Aqui tudo é belo, sensual, cheio de curvas. Como sua paisagem.

Sendo encenação, estas representações traduzem uma idealização do que seja o povo carioca, o Rio de Janeiro e as práticas sociais na cidade. Se a cidade se faz e se refaz no imaginário, estas mesmas construções, ao mesmo tempo em que perpetuam um ideal que habita o imaginário social brasileiro, alimentam-se destas mesmas idealizações, destas construções culturais que fizeram a cidade e os habitantes conquistarem a fama que possuem.

Assim como qualquer tipo de discurso, estas imagens influenciam a visão de mundo do receptor, ao mesmo tempo em que refletem um posicionamento dos autores, contribuindo na perpetuação do que a sociedade considera ideal. Se estas fotografias não traduzem fielmente o Rio de Janeiro real, de alguma forma representam o que queremos ser, um ideal que buscamos para nós. Trata-se menos de um olhar que vem de fora e rotula as especificidades locais e mais o que 
queremos mostrar de nós mesmos.

O imaginário acerca da cidade é habitado por estas imagens produzidas pela mídia. Perguntamos então: em que estas idealizações que habitam o imaginário brasileiro a respeito da mulher carioca e do Rio de Janeiro estão baseadas? Qual a sua ligação com a vida social?

Partimos das observações de Gilberto Freyre (2002) de que modas se acham dentro de um contexto ecológico, sociológico e antropológico, no caso do Brasil, o clima tropical, ou paratropical, oceânico e a morenidade de uma população essencialmente metarracial.

Imbuídos neste pensamento, acreditamos que as roupas sensuais, reduzidas e despojadas atribuídas ao estilo de se vestir da mulher carioca estão relacionadas às próprias características da cidade do Rio de Janeiro, sobretudo sua localização à beira-mar e o clima tropical, que propiciam o desnudamento do corpo e a necessidade de manter em forma durante o ano inteiro. Esta é a imagem do estilo de vida carioca que habita no imaginário acerca da cidade e é exportada para outros estados e países e no âmbito internacional.

Freyre (2002, p. 21), nos anos 1980, afirmou já haver no Brasil uma consciência de que à mulher brasileira cabe seguir modas adaptadas a situações predominantemente tropicais, em vez de seguir passivamente modas européias de trajo, de calçado, de penteado, de adorno, de perfume, de andar, de mulher. Para o autor, o brasileiro está cada vez mais consciente da tropicalidade e da morenidade que caracterizam a sua natureza e sua metarracialidade. Isso se reflete nas modas locais e na valorização do corpo. (FREYRE, 2002, p. 35)

Neste sentido, o estilo de moda carioca - roupas sensuais, despojadas, justas, leves, reduzidas - relacionam-se a estes condicionamentos ecológicos (segundo Freyre, noção ampliada a todas as relações que o homem entretém com a natureza por ele trabalhada e aceita) próprios ao Rio de Janeiro. Há uma estrita relação entre o homem, o social e a natureza.

A imprensa de moda, quando elabora um editorial sobre a moda carioca ou sobre a moda verão, tendo como palco a cidade do Rio de Janeiro e a sugestão de um vestuário mais indicado para ser usado na cidade, privilegia certos aspectos desta moda. Como observamos, ao cenário idílico, que privilegia as belezas naturais da cidade, une-se uma carioca sensual, bronzeada, que porta roupas leves que deixem este corpo à mostra.

Este material reproduz uma moda local baseada num ideal do Rio de Janeiro enquanto paraíso tropical, a cidade maravilhosa, com belas praias, paisagens paradisíacas, pessoas bonitas, bronzeadas e vaporosamente 
vestidas pelas calçadas. Há também espaço, ainda que mais reduzido, a um outro lado da cidade, uma moda periférica, característica dos morros e subúrbios, das tribos e grupos urbanos ou de uma moda que emergente com os novos estilistas, novas grifes, os ateliês e as multimarcas. Sempre que possível, abusa-se do cenário paradisíaco, que eleva o Rio de cenário a personagem das fotografias e do que estas procuram narrar.

As imagens de moda fazem parte deste repertório de imagens que contribuem para que qualquer pessoa, no país ou no exterior, reconheça o Pão de Açúcar, o Morro Dois Irmão, o Corcovado como sendo desta cidade. Segundo Nelson Brissac Peixoto (1990, p. 474), a fotografia é parte do trabalho de reconhecimento da cidade. O Rio de Janeiro é, desde o seu "descobrimento", uma cidade que ricamente iconografada.

Em que estas idealizações que habitam o imaginário brasileiro a respeito da mulher carioca e do Rio de Janeiro se sustentam?

Certamente, estas fotografias apresentam um tipo de mulher ideal e uma moda própria a uma cidade balneária, que privilegia o lazer, os passeios, a alegria. Embora seja próprio à fotografia de moda reproduzir clichês e estereótipos, sobretudo no que se refere à representação da mulher e à apresentação do Rio de Janeiro enquanto um paraíso tropical. Porém, uma investigação mais profunda destas imagens e das demais representações acerca da cidade revela que estas idealizações estão arraigadas no imaginário popular.

Em No fundo das aparências, Maffesoli (1996, p. 278-279) afirma que "o que está em jogo é um imaginário urbano que, de certo modo, ultrapassa os vários atores sociais, serve-lhes de banho matricial". Segundo o autor, às vezes, um local específico, acontecimento, manifestação, espaço de socialidade torna-se emblemático, "reúne mais na constelação urbana, torna-se uma estrela de primeira grandeza". No caso da moda, a Zona Sul emerge como espaço privilegiado, para onde se voltam os holofotes.

Em outra obra, Elogio da rąão sensivel (1998, p. 101), Maffesoli ressalta o papel do espaço para a existência dos indivíduos e da sociedade. Pois somos, antes de mais nada, de algum lugar; nas palavras do autor, "um lugar que nos ultrapassa e cuja forma nos forma", "um lugar que nos une aos outros e provê a informação necessária a toda a vida em sociedade".

Ao se criar essas images, tem-se em mente determinada idéia do que sejam a cidade, os seus habitantes e a sua cultura. Sendo a cidade uma invenção que faz e se refaz no imaginário, como afirma Rosza vel Zoladz (2000, p.4), e permite múltiplas criações resultantes da capacidade de invenção de seus habitantes e de seus visitantes. Portanto, nas construções culturais a respeito do que seja a cidade, sua vida e seus habitantes, trata-se de um certo olhar sobre a cidade, que é também permeado de desejo, afeto, 
sonho, imaginação - categorias que escapam às racionalizações.

Concluímos, assim, reproduzindo as palavra à estilista Marília Valls - uma das pioneiras da moda carioca, integrante do extinto Grupo Moda-Rio, conjunto de criadores sensíveis na busca por uma identidade própria, capaz de traduzir, por meio de suas modas e estilos, esse espírito local - , que estão no texto de abertura do livro 30 estilista à moda do Rio (RODRIGUES; ACIOLI, 2001, p. 11):

No Rio, a emoção e a liberdade se juntam, fazendo a cor e o som dos nossos morros, de nossas praias e de nosso verde: panos de fundo e inspiração para a moda livre, jovem e solta que deverá vestir o Rio $40^{\circ}$. É tempo de assumir a nossa identidade e nossas raízes, criar moda de acordo com o que vivemos. 


\section{Referências}

A FAVELOURA Hickmaniana. Glam Rio, Rio de Janeiro, ano 01, n. 1, p. 26-33, 27 set. 2003.

BARTHES, Roland. A mensagem fotográfica. In: ADORNO, Theodor et al. Teoria da Cultura de Massa. Rio de Janeiro: Paz e Terra, 1990.

. Sistema da moda. São Paulo: Nacional, Universidade de São Paulo, 1979.

BAUDRILLARD, Jean. A troca simbólica e a morte. Lisboa: Edições 70, 1996. BORGES, Virgínia Todeschini. Presença carioca: estudos sobre a moda e a estética corporal na cidade do Rio de Janeiro. 2008. xv, 336 f. Tese. (Doutorado em Artes Visuais) - Escola de Belas Artes, Universidade Federal do Rio de Janeiro, Rio de Janeiro, 2008.

BRANDÃO, Ignácio de Loyola. Ponto de vista. Vogue Brasil, São Paulo, n. 282, p. 165, 2001.

Ponto de vista. Vogue Brasil, São Paulo, n. 316, p. 191, 2004.

CARTA, Patricia. Mix Brasil. Vogue Brasil, São Paulo, n. 316, p. 15, 2004.

CEZIMBRA, Marcia. Beleza 'brazileira'. O Globo, Rio de Janeiro, 12 out. 2003. Jornal da Família, p. 1.

CIDADE aberta. O Globo, Rio de Janeiro, 04 mar. 2000. Ela, p. 1.

DUVIGNAUD, Jean. Terres du sucre - Prefácio. In: TEXTOS didáticos.

Programa de Pós-graduação em Artes Visuais EBA/UFRJ, 1998. 16p. Trad. e notas ZOLADZ, Rosza vel. p. 1.

ELA é carioca. Revista Daslu, São Paulo, n. 32, p. 166-173, nov. 2007.

ELA é carioca. Vogue Brasil, São Paulo, n. 305, p. 204-213, 2003.

FREYRE, Gilberto. Modos de homem \& modas de mulher. Rio de Janeiro:

Record, 2002.

GOFFMAN, Irving. La ritualisation de la féminité. Actes de la recherche en Sciences Sociales, n. 14, p. 34-49, avr. 1977. P. 36.

GOLDENBERG, Mirian (Org.). Nu \& vestido: dez antropólogos revelam a cultura do corpo carioca. Rio de Janeiro: Record, 2002.

LIPOVETSKY, Gilles. Entrevista concedida a Adriana Bechara. Domingo, Rio de Janeiro, ano 29, p. 30-31, 29 ago. 2004.

MAFFESOLI, Michel. No fundo das aparências. Petrópolis, RJ: Vozes, 1996.

MALYSSE, Stéphane. Em busca dos (H)alteres-ego: Olhares franceses nos bastidores da corpolatria carioca. In: GOLDENBER, Mirian (Org). $N u$ \& vestido: dez antropólogos revelam a cultura do corpo carioca. Rio de Janeiro: Record, 2002. p.79-137.

MENINOS do Rio. Vogue Brasil, São Paulo, n. 282, p. 166-177, 2001.

O MELHOR do verão. Elle, São Paulo, ano 13, n. 1, p. 58-65, jan. 2000. 
PEIXOTO, Nelson Brissac. As imagens e o outro. In: NOVAES, Adauto (Org.). O desejo. São Paulo: Companhia das Letras, 1990. p. 471-480.

QUAL é a sua praia? O Globo, Rio de Janeiro, 21, dez. 2002. Ela, p. 1.

RIO, le grand. Vogue America, New York, v. 197, n. 6, p. 159-169, jun. 2007. RODRIGUES, Iesa; ACIOLI, Paula. 30 estilistas - $A$ moda do Rio. Rio de Janeiro: Senac, 2001.

VILLAÇA, Nízia. Corpo à moda mídia na cidade do Rio de Janeiro. Disponível em: <http://www.pos.eco.ufrj.br/docentes/publicacoes/nvillaca_2.pdf>. Acesso em 08 jan. 2008.

ZOLADZ, Rosza W. vel. Rio, la ville merveilleuse et ses représentations culturelles dans l'imaginaire brésilien. Communication présentée au XVIe Congrès de l'Association Internationale de Sociologie de Langue Française (AISLF) à l' Université de Québec, Canadá, 2000. 